Research Article

\title{
In Vitro and In Vivo Anti-Inflammatory Activities of Benjakul: A Potential Medicinal Product from Thai Traditional Medicine
}

\author{
Pranporn Kuropakornpong, ${ }^{1}$ Arumporn Itharat $\mathbb{C D}^{2,3}$ Sumalee Panthong $\mathbb{D}^{2,3}$ \\ Seewaboon Sireeratawong $\mathbb{D}^{4},{ }^{4}$ and Buncha Ooraikul ${ }^{5}$ \\ ${ }^{1}$ Graduate School, Faculty of Medicine, Thammasat University, Pathum Thani 12120, Thailand \\ ${ }^{2}$ Department of Applied Thai Traditional Medicine, Faculty of Medicine, Thammasat University, \\ Pathum Thani 12120, Thailand \\ ${ }^{3}$ Center of Excellence in Applied Thai Traditional Medicine Research (CEATMR), Thammasat University, \\ Pathum Thani 12120, Thailand \\ ${ }^{4}$ Department of Pharmacology, Faculty of Medicine, Chiang Mai University, Chiang Mai 50200, Thailand \\ ${ }^{5}$ Department of Agricultural Food and Nutritional Science, Faculty of Agricultural Life and Environmental Sciences, \\ University of Alberta, Edmonton, AB T6G 2P5, Canada \\ Correspondence should be addressed to Arunporn Itharat; iarunporn@yahoo.com
}

Received 22 April 2020; Revised 3 June 2020; Accepted 18 June 2020; Published 14 July 2020

Guest Editor: Lei Xu

Copyright (c) 2020 Pranporn Kuropakornpong et al. This is an open access article distributed under the Creative Commons Attribution License, which permits unrestricted use, distribution, and reproduction in any medium, provided the original work is properly cited.

\begin{abstract}
Benjakul (BJK) is a Thai traditional remedy consisting of five plants: Piper chaba Hunt., Piper sarmentosum Roxb., Piper interruptum Opiz., Plumbago indica Linn., and Zingiber officinale Roscoe. It is used as a first-line drug to balance patient's symptoms before other treatments. BJK ethanolic extract has been reported to show anti-inflammatory activity through various mediators, e.g., nitric oxide, TNF- $\alpha$, IL- $1 \beta$, and IL-6. Therefore, BJK could serve as a potential novel anti-inflammatory herbal medicine. However, studies on prostaglandin E2 (PGE2), one of the key mediators in acute inflammation, and anti-inflammation in animal models (in vivo) have not been done. This study investigated the anti-inflammatory activity of BJK extract and some of its chemical compounds against PGE2 production in murine macrophage (RAW 264.7) cell line and two in vivo models of antiinflammatory studies. Ethanolic extract of $\mathrm{BJK}(\mathrm{BJK}[\mathrm{E}])$ showed high inhibitory activity against PGE2 production with an $\mathrm{IC}_{50}$ value of $5.82 \pm 0.10 \mu \mathrm{g} / \mathrm{mL}$ but its water extract (BJK[W]) was inactive. Two chemicals from BJK[E], i.e., plumbagin and myristicin, which served as biological markers, showed strong activity with $\mathrm{IC}_{50}$ values of $0.08 \pm 0.01$ and $1.80 \pm 0.06 \mu \mathrm{g} / \mathrm{mL}$, respectively. BJK [E] was administered both topically and orally to rats inhibited with inflammation induced by ethyl phenylpropiolate (rat ear edema model) and carrageenan (hind paw edema model). Moreover, the biological activity of BJK extract did not reduce after sixmonth storage under accelerated condition $\left(40^{\circ} \mathrm{C}, 75 \% \mathrm{RH}\right)$. This indicated its stability and a 24-month shelf-life under normal condition. These results supported not only the use of BJK in Thai traditional medicine but also the possibility of further development of phytopharmaceutical products from BJK.
\end{abstract}

\section{Introduction}

Inflammation of muscles can affect people of all ages. To mitigate or reduce pain, over-the-counter (OTC) or prescription drugs such as nonsteroidal anti-inflammatory drugs (NSAID) or corticosteroids pain relievers are recommended. Unfortunately, some of these drugs have some short-term or long-term negative side effects such as bleeding, indigestion, heart problems, and kidney issues. Some, such as opioids, may cause serious addiction. Therefore, more and more patients are turning to natural products to manage their pain, resulting in increased efforts to develop natural anti-inflammatory medicines.

Thailand's National List of Essential Medicines (NLEM) has approved six traditional remedies as medicines for muscle and joint pain. Each of the remedies contains a 
complex mixture of more than five plants, which in turns imposes limitations on the use of these traditional remedies. There are some powerful topical anti-inflammatory products which contain a single plant extract such as chili. Unfortunately, it also causes skin irritation. It is possible that, by using a combination of herbs, negative side effects of active ingredients are kept to minimum by the supplementary herbs that may appear superfluous. Therefore, the use of a combination of herbs is much preferred.

Benjakul (BJK), a Thai traditional remedy for pain, is a combination of five spicy and hot plants: Piper chaba Hunt. (PCH), Piper sarmentosum Roxb. (PSR), Piper interruptum Opiz. (PIO), Plumbago indica Linn. (PIL), and Zingiber officinale Roscoe (ZOR). It has been used as the first drug to reduce pain and balance patients' symptoms before administering other treatments such as inflammatory and cancer treatments [1]. According to the previous studies, the ethanolic extract of BJK has been reported to show antiinflammatory activity through nitric oxide production inhibition but the water extract did not have this activity [2]. It was also reported to have significant inhibitory activity on the release of TNF- $\alpha$, IL- $1 \beta$, and IL- 6 from LPS-treated CaCo-2 cells [3]. Methanolic extract of $\mathrm{PCH}$ at the doses of 125 and $250 \mathrm{mg} / \mathrm{kg}$ body weight showed significant antiinflammatory activity in animal study with reduction of edema (33\% and $35 \%$, respectively) [4]. PCH, PIO, and PSR showed analgesic and anti-inflammatory activities in mice $[5,6]$. ZOR exhibited high inhibitory activity on nitric oxide and prostaglandin production, both in vitro and in vivo $[7,8]$.

Due to its simple plant combination, together with the strong anti-inflammatory activity, BJK has been of particular interest in the development of anti-inflammatory medicines. Though its anti-inflammation has been reported, studies on its effects on prostaglandin E2 (PGE2), one of the important factors in inflammation process, and in vivo model, have not been done.

According to traditional usage, the patients were given $\mathrm{BJK}$ medicine as dried powder and decoctions were prepared by the patients themselves. BJK liquor is prepared by the traditional doctors and sometimes given to patients. Both dosage forms of BJK preparations are to be taken orally. In this study, BJK was extracted with water and ethanol mimicking the methods used by Thai traditional medicine.

The chemical fingerprints of BJK ethanolic extract have been elucidated by high-performance liquid chromatography (HPLC). There were five markers that have been reported to be present in BJK: myristicin, plumbagin, piperine, 6-gingerol, and 6-shogaol (Figure 1). Its highest chemical marker, piperine, which is a marker for Piper species, was used as its analytical marker, while its biological markers for anti-inflammation were selected following the analysis of the inhibition of PGE2 production.

Chemical and biological stability are used to determine shelf-life of drugs. Heat and moisture are major factors affecting drug stability. A drug should be able to withstand storage conditions, normally ambient temperature and humidity, for a period of at least 12 months. In testing drug stability, accelerated storage test under the temperature and humidity of $40 \pm 2^{\circ} \mathrm{C}$ and $75 \pm 5 \% \mathrm{RH}$ for at least 6 months is used to shorten the storage time before determining the change in its bioactivities. The accelerated test method provides a good estimate for drug shelf-life.

The objectives of this study were to investigate the inhibitory activity of BJK extract, its individual plant extracts, its biological markers against PGE2 production from LPSstimulated RAW 264.7 macrophages, and its stability under the accelerated storage conditions. In vivo anti-inflammatory activity was also studied to confirm its effectiveness in animal model. Data obtained will be useful to the industry in the development of phytopharmaceutical products.

\section{Materials and Methods}

2.1. Plant Materials. Five plants ingredients of BJK were collected from several parts of Thailand and authenticated by the herbarium of Southern Centre of Thai Medicinal Plant, Faculty of Pharmaceutical Science, Prince of Songkhla University, Thailand (Table 1).

2.2. Chemicals. Standard compounds, myristicin, plumbagin, 6-gingerol, 6-shogaol, were purchased from SigmaAldrich, USA, and piperine was purchased from Merck, Thailand. HPLC-grade water, methanol, and acetonitrile were purchased from Labscan, Thailand.

Dulbecco's Modified Eagle's Medium (DMEM), fetal bovine serum (FBS), penicillin streptomycin (P/S), and $0.5 \%$ trypsin-EDTA were purchased from Gibco BRL Life Technologies (Grand Island, NY, USA). Phosphate buffer saline (PBS) was purchased from Amresco (Ohio, USA). Dimethyl sulfoxide (DMSO) was purchased from Fluka (Munich, Germany). Lipopolysaccharide (LPS) and 3-(4,5dimethyl-2-thiazolyl)-2,5 diphenyl-2H-tetrazolium bromide (MTT) were purchased from Sigma-Aldrich Inc. (St. Louis, MO, USA). Prostaglandin E2 EIA kit monoclonal was purchased from Cayman Chemical Company (Michigan, USA).

Male Sprague-Dawley rats were obtained from National Laboratory Animal Center, Nakorn Pathom, Thailand. They were kept in a room maintained under environmental conditions of $25 \pm 1^{\circ} \mathrm{C}$ and $12 \mathrm{hr}$ dark-light cycle with free access to water and food. Rats were kept in the experimental facility for 1 week to allow them to be acclimated prior to the experiments. The Animal Ethics Committee of Faculty of Medicine, Thammasat University, Thailand, approved the experimental protocols (no. 0002/2008). After the experiments, all animals were sacrificed.

2.3. Preparation of Plant Extract. Each plant was cleaned, dried, and ground into coarse powder. A kilogram of BJK was prepared by mixing an equal amount of the five plants. Each plant and the BJK powder were subjected to two extraction methods. The first method was maceration with ethanol ( $2: 1$ weight ratio) for 3 days. The extracts were filtered and concentrated by vacuum evaporation. This process was repeated twice on the residue. The extract was designated ethanolic extract ([E]). The second method was 


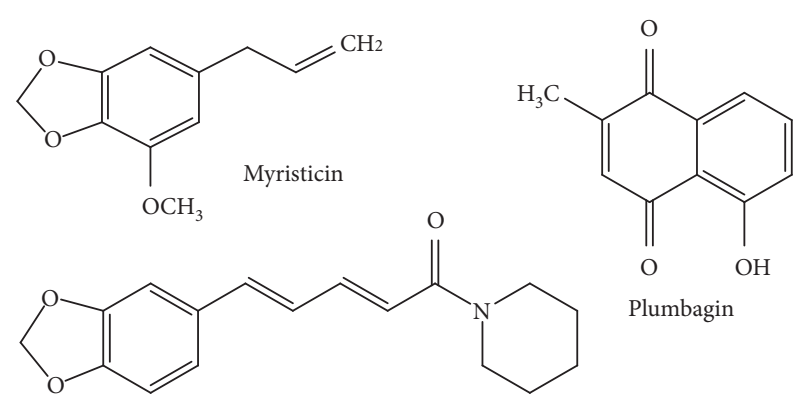<smiles>CCCCCC(O)CC(=O)CCc1ccc(O)c(OC)c1</smiles><smiles>CCCCC/C=C/C(=O)CCc1ccc(O)c(OC)c1</smiles>

FIgURE 1: Chemical structures of pure compounds from BJK extract.

TABle 1: Plant materials used in BJK remedy.

\begin{tabular}{lcccc}
\hline & General name & Code & Part of use in BJK & Voucher specimen \\
\hline 1 & Piper chaba Hunt. & PCH & Fruit & SKP 146160301 \\
2 & Piper sarmentosum Roxb. & PSR & Root & SKP 146161901 \\
3 & Piper interruptum Opiz. & PIO & Stem & SKP 146160901 \\
4 & Plumbago indica Linn. & PIL & Root & SKP 148160901 \\
5 & Zingiber officinale Rosc. & ZOR & Rhizome & SKP 206261501 \\
\hline
\end{tabular}

decoction with deionized water. The aqueous extracts were dried with a lyophilizer. The extracts were designated water extract $([\mathrm{W}])$.

\subsection{Determination of BJK Markers Using HPLC}

2.4.1. HPLC Systems and Conditions. BJK fingerprint was obtained by using high-performance liquid chromatography (HPLC) of the Agilent 1200 series model. The instrument is composed of a solvent degasser (G1322A), a quaternary solvent pump (G1311A), an auto sampler (G1329A), a column thermostat (G1316A), and a photodiode array detector (G1315D).

A reverse-phase column (Phenomenex): Luna ${ }^{\circledR} 5 \mu \mathrm{m}$ $\mathrm{C} 18,100 \AA, 250 \times 4.6 \mathrm{~mm}$ was used as the stationary phase. Samples of $10 \mu \mathrm{l}$ were injected and eluted with a gradient system composed of water and acetonitrile. The analyses of markers were performed at $210 \mathrm{~nm}$ (myristicin, 6-shogaol, and 6-gingerol), $254 \mathrm{~nm}$ (plumbagin), and $340 \mathrm{~nm}$ (piperine).

2.4.2. Standard Preparation. Two $\mathrm{mg}$ of standard was weighed into a volumetric flask, using methanol as a solvent. Seven concentrations $(400,200,150,50,25,10$, and
$1 \mu \mathrm{g} / \mathrm{mL}$ ) of standard were prepared to produce a standard curve.

2.4.3. Sample Preparation. Ten $\mathrm{mg}$ of BJK extract was dissolved in $1 \mathrm{~mL}$ of methanol to make $10 \mathrm{mg} / \mathrm{mL}$ concentration and filtered through a $0.45 \mu \mathrm{m}$ membrane filter.

2.5. In Vitro Anti-Inflammatory Activity of BJK Extract and Its Plant Components by PGE2 Inhibition Assay [9]. BJK and each plant ingredient were subjected to two extraction methods which were maceration with $95 \%$ ethanol as ethanolic extract [E] and decoction as water extract [W] (as described in Section 2.3) and tested for the in vitro antiinflammatory activity by PGE2 inhibition assay as follows:

Step 1: the RAW 264.7 cells in Dulbecco's Modified Eagle's Medium (DMEM) were seeded into 96-well plates with density of $1 \times 10^{5}$ cells/well and incubated at $37^{\circ} \mathrm{C}, 5 \% \mathrm{CO}_{2}$, for $24 \mathrm{hr}$. Subsequently, the old medium was replaced with fresh medium containing $2 \mu \mathrm{g} / \mathrm{mL}$ of LPS; then test samples were added and incubated at $37^{\circ} \mathrm{C}, 5 \% \mathrm{CO}_{2}$, for $24 \mathrm{hr}$.

Step 2: PGE2 production by enzyme-linked immunosorbent assay (ELISA) was determined by 
transferring $50 \mu \mathrm{L}$ of supernatant into a goat antimouse IgG coated plate. After that, $50 \mu \mathrm{L}$ each of prostaglandin E2 AChE tracer and prostaglandin E2 monoclonal antibody was added to each well and incubated at $4^{\circ} \mathrm{C}$ for $18 \mathrm{hr}$. The plate was washed with wash buffer; then Ellman's reagent was added and incubated at $37^{\circ} \mathrm{C}$ for $60-90$ minutes. The optical density (OD) was measured at $412 \mathrm{~nm}$. The $50 \%$ inhibitory concentration $\left(\mathrm{IC}_{50}\right)$ was calculated. All data were expressed as mean \pm standard error of means (SEM).

Step 3: RAW 264.7 cells viability was determined by the MTT assay. After separating supernatant from the incubated plate (in Step 1), $5 \mathrm{mg} / \mathrm{mL}$ MTT solution was added to each well and incubated at $37^{\circ} \mathrm{C}, 5 \% \mathrm{CO}_{2}$, for $2 \mathrm{hr}$. Subsequently, the old medium was removed and $100 \mu \mathrm{L}$ of 0.04 molar of hydrochloric acid $(\mathrm{HCl})$ in isopropanol was added to dissolve the formazan product. The OD was measured at $570 \mathrm{~nm}$. Percentage of cell survival should be above $70 \%$ compared to control.

2.6. In Vivo Anti-Inflammatory Activity Testing. BJK[E] which showed high in vitro anti-inflammatory activity was then tested for the in vivo anti-inflammatory activities.

2.6.1. Ethyl Phenylpropiolate- (EPP-) Induced Ear Edema in Rats [10]. Male rats (40-60 g) were divided into five groups of three rats each $(n=6)$. Twenty $\mu \mathrm{L}$ of acetone, phenylbutazone (final concentration of $1 \mathrm{mg} /$ ear), and three doses of BJK ethanolic extracts $(\mathrm{BJK}[\mathrm{E}])$ at various final concentrations of 1,2 , and $4 \mathrm{mg}$ /ear were applied topically to the control, reference, and test group, respectively. Ethyl phenylpropiolate (EPP) was then applied topically $(1 \mathrm{mg} / 20 \mu \mathrm{L} /$ ear) on the inner and outer surface of both ears to induce edema. The thickness of each ear was measured with a digital Vernier caliper at 15, 30, 60, and $120 \mathrm{~min}$ after edema induction.

Results were expressed as mean \pm SEM compared with the control group at each time interval. Statistical significance was determined by one-way analysis of variance (ANOVA) at the 95\% confidence interval.

2.6.2. Carrageenan-Induced Paw Edema in Rats [11]. Male rats (100-120 g) were divided into five groups of six each. Each group was orally administered 5\% Tween 80, aspirin $(300 \mathrm{mg} / \mathrm{kg})$, and various doses of BJK ethanolic extract $(\mathrm{BJK}[\mathrm{E}])(300,600$, and $1,200 \mathrm{mg} / \mathrm{kg})$ as the control, reference, and test group, respectively. Samples were feed one hour prior to carrageenan injection. A $0.05 \mathrm{~mL}$ of $1 \%$ carrageenan in sterile normal saline solution (NSS) was injected intradermally into the plantar side of the right hind paw of the rats. The edema volumes were determined using a plethysmometer (model 7140, Ugo Basile, Italy) at 1, 3, and $5 \mathrm{hr}$ after carrageenan injection.

Results were expressed as mean \pm SEM compared with the control group at each time interval. Statistical significance was determined by one-way analysis of variance (ANOVA) at the 95\% confidence interval.

2.7. Stability Testing of BJK Extract under the Accelerated Conditions. BJK extracts were kept at $40 \pm 2^{\circ} \mathrm{C}$ and $75 \pm 5 \%$ $\mathrm{RH}$ for 6 months [12]. An aliquot of 1 gram was taken every 30 days and tested for inhibition activity against PGE2 production. One-way ANOVA was used to determine the difference between day 0 and other days.

\section{Results and Discussion}

3.1. Determination of BJKMarkers Using HPLC. There were 5 reported markers in BJK extract, i.e., myristicin, plumbagin, piperine, 6-gingerol, and 6-shogaol (Figure 1). HPLC chromatogram at $210 \mathrm{~nm}$ showed the presence of these markers in BJK extract (Figure 2). The peak identity was confirmed by the retention time and the scanned spectrum of each peak matching to that of pure standard. The quantitative analysis of each marker was done at different wavelengths that provided the best selectivity, i.e., 6-gingerol, myristicin, and 6-shogaol at $210 \mathrm{~nm}$; plumbagin, at $254 \mathrm{~nm}$; and piperine at $340 \mathrm{~nm}$.

3.2. In Vitro Anti-Inflammatory Activity of BJK Extract and Its Plant Components by PGE2 Inhibition Assay. The results showed that all water extracts tested, including piperine and 6-gingerol, did not have the PGE2 production inhibition activity. Plumbagin was the most active compound with $\mathrm{IC}_{50}$ value of $0.08 \pm 0.01 \mu \mathrm{g} / \mathrm{mL}$ which was better than the standard drugs prednisolone and indomethacin $\left(\mathrm{IC}_{50}\right.$ values of 0.95 and $1.00 \mu \mathrm{g} / \mathrm{mL}$, respectively). Myristicin was the second active compound in $\mathrm{BJK}$ with $\mathrm{IC}_{50}$ value of $1.80 \pm 0.06 \mu \mathrm{g} / \mathrm{mL}$ while 6-shogaol was the third active compound with $\mathrm{IC}_{50}$ value of $12.29 \pm 0.02 \mu \mathrm{g} / \mathrm{mL}$. Comparison between the activities of various ethanolic extracts revealed that $Z O R$ was the most active extract with $\mathrm{IC}_{50}$ value only $0.83 \pm 0.26 \mu \mathrm{g} / \mathrm{mL}$ which was better than prednisolone and indomethacin. PCH and BJK were the second and third active extracts with $\mathrm{IC}_{50}$ values of $5.22 \pm 0.53$ and $5.82 \pm 0.10 \mu \mathrm{g} / \mathrm{mL}$, respectively. The ethanolic extracts of PIL, $\mathrm{PIO}$, and PSR were less active with $\mathrm{IC}_{50}$ values of $7.96 \pm 2.44$, $10.88 \pm 8.88$, and $11.79 \pm 3.20 \mu \mathrm{g} / \mathrm{mL}$, respectively (Table 2, Figure 3). The Thai traditional medicine [TTM] is also known to have used ginger for topical treatment of joint inflammation, and, according to the theory of TTM, the herbs that generate heat are useful for Vata (a wind element) problem such as arthritis. Other plant components also contained some inhibition activity on PGE2 production. Increment of ZOR and PCH composition in BJK could possibly promote the anti-inflammatory activity of BJK.

These results support the use of BJK as anti-inflammation drug in Thai traditional medicine. BJK contains more than one bioactive compound that exerted anti-inflammatory activity, which may explain the decrease in its toxicity against normal cells as compared to the extracts from individual plants. A previous study showed that plumbagin decreased the expression of NF- $\kappa \mathrm{B}$-regulated 


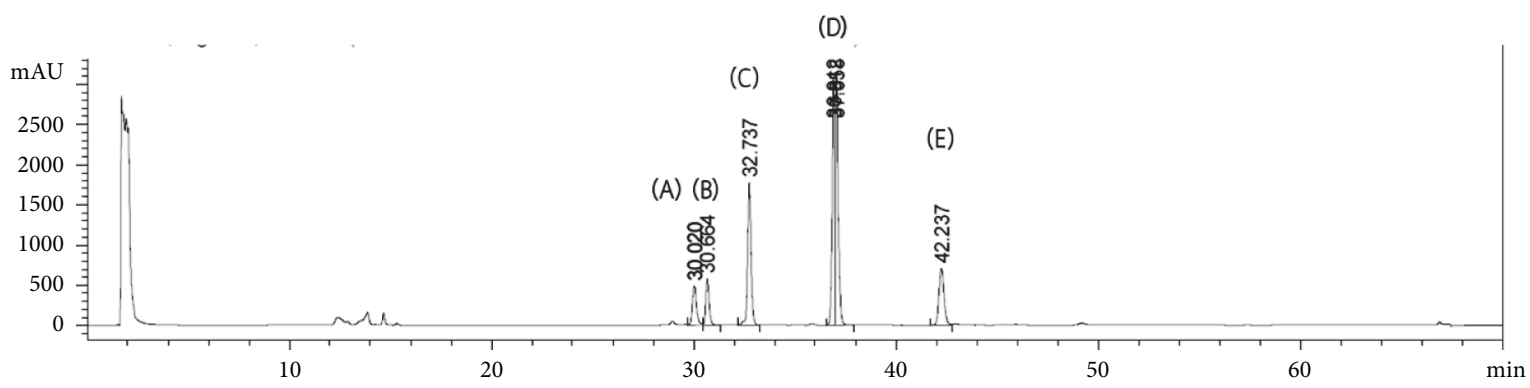

(a)

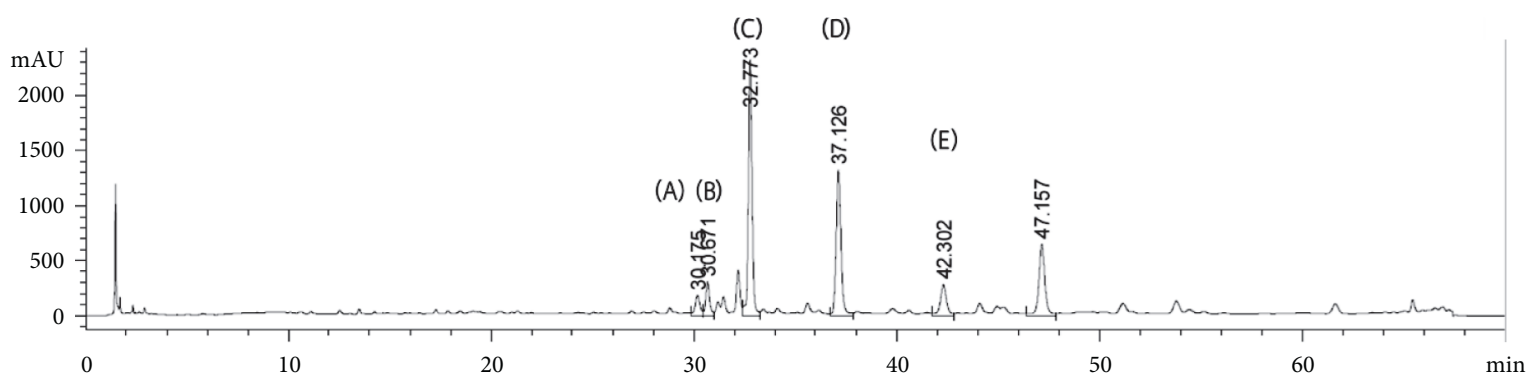

(b)

Figure 2: HPLC profile of five standards (a) and BJK extract (b) detected with diode array at $210 \mathrm{~nm}$. Plumbagin (A), 6-gingerol (B), Piperine (C), myristicin (D), and 6-shogaol (E).

TABLE 2: Percentage of inhibition at various concentrations and $\mathrm{IC}_{50}$ values of the ethanolic and water extract of plant component in $\mathrm{BJK}$ preparation on PGE2 production.

\begin{tabular}{|c|c|c|c|c|c|c|c|c|c|c|}
\hline \multirow{2}{*}{ Plant } & \multirow{2}{*}{ Extract } & \multicolumn{8}{|c|}{$\%$ inhibition at various concentrations (mean + SEM) (\% survival of cells at the highest concentration) } & \multirow{2}{*}{$\begin{array}{c}\mathrm{IC}_{50} \\
(\mu \mathrm{g} / \mathrm{mL})\end{array}$} \\
\hline & & $100 \mu \mathrm{g} / \mathrm{mL}$ & $50 \mu \mathrm{g} / \mathrm{mL}$ & $30 \mu \mathrm{g} / \mathrm{mL}$ & $20 \mu \mathrm{g} / \mathrm{mL}$ & $15 \mu \mathrm{g} / \mathrm{mL}$ & $10 \mu \mathrm{g} / \mathrm{mL}$ & $1 \mu \mathrm{g} / \mathrm{mL}$ & $0.1 \mu \mathrm{g} / \mathrm{mL}$ & \\
\hline \multirow{2}{*}{ PCH. } & Ethanol & & & $\begin{array}{c}86.54 \pm 7.30 \\
(77.33 \pm 3.64)\end{array}$ & & & $73.72 \pm 0.03$ & $36.38 \pm 1.77$ & $35.91 \pm 0.82$ & $5.22 \pm 0.53$ \\
\hline & Water & $\begin{array}{c}10.92 \pm 4.18 \\
(97.56 \pm 2.06)\end{array}$ & & & & & & & & $>100$ \\
\hline \multirow{2}{*}{ PSR. } & Ethanol & $\begin{array}{c}87.50 \pm 4.21 \\
(98.04 \pm 4.08)\end{array}$ & $95.36 \pm 1.33$ & & & & $47.46 \pm 5.52$ & $30.09 \pm 2.37$ & & $11.79 \pm 3.20$ \\
\hline & Water & $\begin{array}{c}5.09 \pm 2.90 \\
(59.23 \pm 4.24)\end{array}$ & & & & & & & & $>100$ \\
\hline \multirow{2}{*}{ PIO } & Ethanol & & & $\begin{array}{c}81.58 \pm 2.67 \\
(79.14 \pm 2.62)\end{array}$ & & & $41.39 \pm 2.53$ & $15.60 \pm 5.41$ & $-6.92 \pm 5.97$ & $10.88 \pm 8.88$ \\
\hline & Water & & & $\begin{array}{c}10.28 \pm 2.69 \\
(74.14 \pm 2.44)\end{array}$ & & & & & & $>100$ \\
\hline \multirow{2}{*}{ PIL. } & Ethanol & & & & $\begin{array}{c}98.70 \pm 1.78 \\
(83.35 \pm 6.11)\end{array}$ & & $66.64 \pm 17.96$ & $1.02 \pm 14.62$ & $-9.47 \pm 20.61$ & $7.96 \pm 2.44$ \\
\hline & Water & $\begin{array}{c}31.15 \pm 3.84 \\
(93.41 \pm 2.13)\end{array}$ & & & & & & & & $>100$ \\
\hline \multirow{2}{*}{ ZOR } & Ethanol & & & & & $\begin{array}{l}75.21 \pm 15.07 \\
(81.06 \pm 6.28)\end{array}$ & $79.86 \pm 13.27$ & $57.99 \pm 11.21$ & $18.40 \pm 9.33$ & $0.83 \pm 0.26$ \\
\hline & Water & & & & & & & $\begin{array}{c}11.72 \pm 1.78 \\
(80.69 \pm 3.10)\end{array}$ & & $>100$ \\
\hline \multirow{2}{*}{ BJK } & Ethanol & & & & $\begin{array}{l}83.20 \pm 2.76 \\
(95.41 \pm 1.2)\end{array}$ & & $80.16 \pm 2.25$ & $13.45 \pm 1.56$ & $8.77 \pm 2.02$ & $5.82 \pm 0.10$ \\
\hline & Water & & & & & & $\begin{array}{c}9.67 \pm 0.79 \\
(75.40 \pm 4.1)\end{array}$ & $6.66 \pm 3.29$ & $8.21 \pm 2.98$ & $>10$ \\
\hline
\end{tabular}

BJK: Benjakul, PCH: Piper chaba Hunt., PSR: Piper sarmentosum Roxb., PIO: Piper interruptum Opiz., PIL: Plumbago indica Linn., and ZOR: Zingiber officinale Roscoe.

gene products that play a role in cell proliferation, antiapoptosis, and inflammation [13], including decreasing the expression of COX2 in mice with prostate cancer [14]. Myristicin also showed high inhibitory activity on PGE2 release. A previous report showed that myristicin significantly decreased nitric oxide, inflammatory cytokines production, and growth factor in macrophage [15]. Even though the mechanism of BJK and its compounds on PGE2 


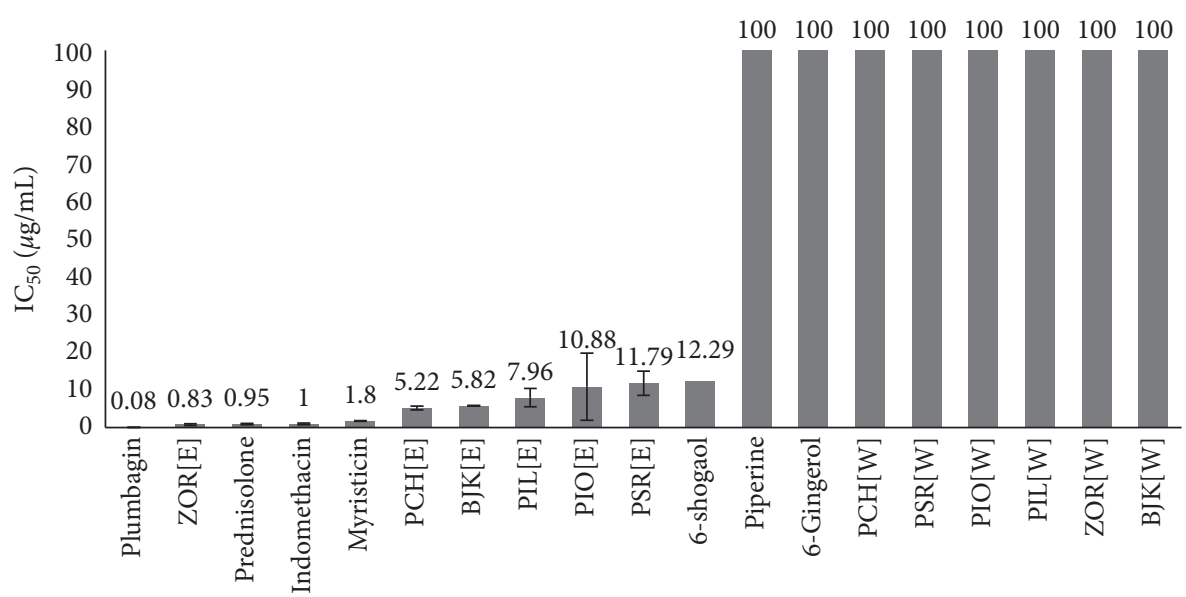

FIGURE 3: IC ${ }_{50}$ of BJK extract, its components, and pure compounds on the inhibition of PGE2 production. BJK: Benjakul, PCH: Piper chaba Hunt., PSR: Piper sarmentosum Roxb., PIO: Piper interruptum Opiz., PIL: Plumbago indica Linn., and ZOR: Zingiber officinale Roscoe. The letter in [ ] refers to the extraction method; [E]: ethanolic extract and [W]: water extract.

inhibition in this study was not clear, from previous reports, BJK showed significant inhibitory activity on IL-6, IL- $1 \beta$, and nitric oxide. [2, 3]. Future work should focus on the selective COX-2 inhibition, which is the key enzyme of PGE2 and IL-6 production and other inflammatory mediators in in vivo model.

\subsection{In Vivo Anti-Inflammatory Activity of BJK Extract}

3.3.1. Ethyl Phenylpropiolate- (EPP-) Induced Ear Edema in Rats. The EPP-induced rat ear edema is conventionally used to estimate anti-inflammatory activity of test substances during the acute phase of inflammation. The inflammatory mediators released in EPP-induced ear edema model are histamine, serotonin, bradykinin, and prostaglandins (PGs); these mediators are capable of promoting vasodilatation and increasing vascular permeability as well as synergistically producing edema $[10,16]$. In vivo study on anti-inflammatory activity using EPP-induced rat ear edema showed that BJK ethanolic extract (BJK[E]) at 1,2 , and $4 \mathrm{mg} /$ ear could reduce edema with significant difference from control. At the dose of $4 \mathrm{mg} /$ ear, BJK[E] could reduce edema better than phenylbutazone with significant difference at $60 \mathrm{~min}$ (Figure 4).

Topical administration of BJK[E] showed anti-inflammatory activity by inhibiting the inflammatory mediators of the acute phase of inflammation via inhibition of release and/or formation of inflammatory mediators involved in edema formation which was related to the in vitro results.

3.3.2. Carrageenan-Induced Paw Edema in Rats. The in vivo anti-inflammatory activity of BJK extract was confirmed by the carrageenan-induced paw edema model. Several inflammatory mediators, for example, histamine, serotonin, kinins, PGs, complement, and proinflammatory cytokines, play a major role in paw edema caused by carrageenan $[17,18]$. The initial phase is caused by the release of histamine and serotonin followed by the release of bradykinin during 1-2 hr after carrageenan injection [19]. The release of PGs is closely associated with leukocytes migration to the inflamed site. The presence of PGs, particularly $\mathrm{PGE}_{2}$, in the inflammatory exudates from the injected foot can be demonstrated at $3 \mathrm{hr}$ and thereafter [20]. Oral administration of $\mathrm{BJK}[\mathrm{E}]$ at the dose of $1,200 \mathrm{mg} / \mathrm{kg}$ could reduce the swollen of carrageenan-induced paw edema with significant difference from control at 1, 3, and $5 \mathrm{hr}$ and was not different from the standard drug, aspirin. However, the BJK extract at $300 \mathrm{mg} / \mathrm{kg}$ showed no activity at any time interval (Figure 5).

Oral administration of $\mathrm{BJK}[\mathrm{E}]$ at the concentration of $1,200 \mathrm{mg} / \mathrm{kg}$ showed the anti-inflammatory activity by inhibiting the acute phase of inflammation. Based on the inhibitory effect of the BJK[E] seen at the $3^{\text {rd }}$ hr and $5^{\text {th }} \mathrm{hr}$, it suggests that the main mechanism of action may be due to inhibition of PGs synthesis. Moreover, the inhibitory effect of the BJK[E] may partly involve other acute inflammatory mediators such as histamine, serotonin, bradykinin, and proinflammatory cytokines which are released during the $1^{\text {st }} \mathrm{hr}$ after carrageenan injection.

3.4. Stability Testing of BJK Extract under the Accelerated Conditions. No physical difference between the normal and stored BJK extract samples was detected after the completion of the accelerated stability test. Anti-inflammatory activity of the samples was unchanged up to day 120 and then increased significantly on day 180 with $\mathrm{IC}_{50}$ values decreasing from about 4.3 to $1.76 \pm 0.15 \mu \mathrm{g} / \mathrm{mL}$. Despite the increasing activity, the reductions in the content of the three markers were observed: piperine and myristicin content remained $84.88 \%$ and $91.53 \%$, respectively, on day 180 while plumbagin, the strongest active marker, has not been detected since day 60 (Table 3 ). The loss of plumbagin could be due to its sublimation property even at room temperature. The results suggested that the biological activity of BJK extract was related to other substances more than those selected markers in this study. It also implied that for stability study 


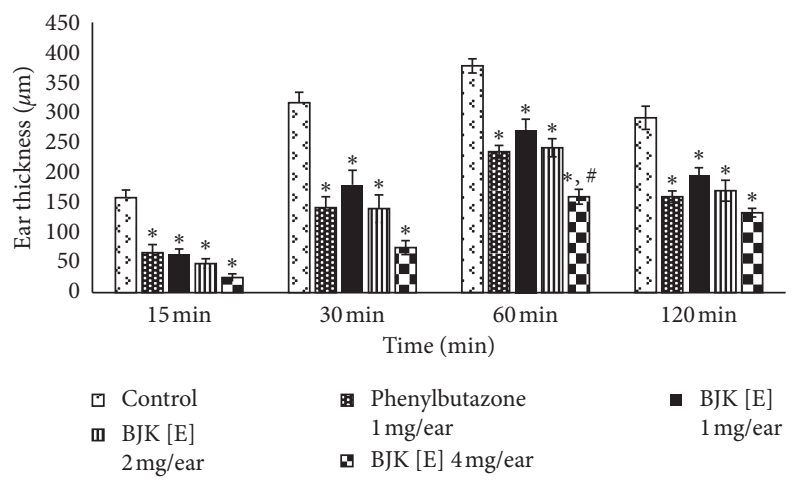

Figure 4: The thickness of ear at 15, 30, 60, and 120 min after edema induction. * Significant difference from the control group $(P<0.05)$. "Significant difference from phenylbutazone $(P<0.05)$ according to one-way ANOVA with Tukey's HSD test. BJK $[E]$ : Benjakul ethanolic extract.

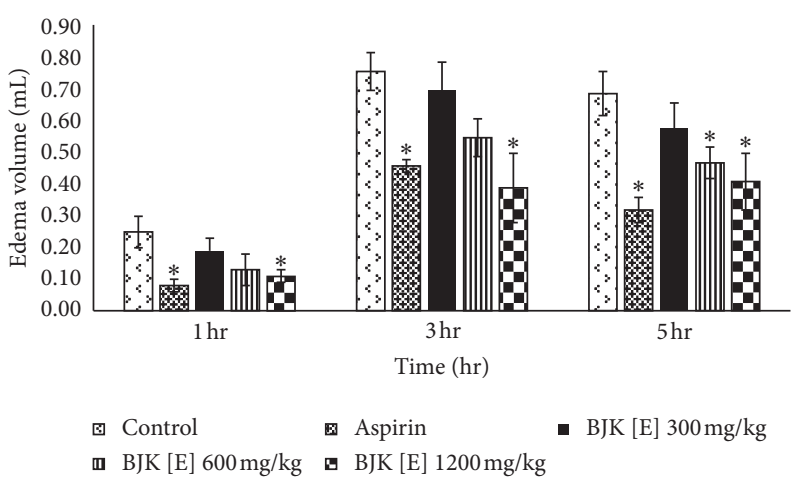

Figure 5: The edema volume of rat paw at 1,3 , and $5 \mathrm{hr} .{ }^{*}$ Significant difference from the control group $(P<0.05)$ according to one-way ANOVA with Tukey's HSD test. BJK [E]: Benjakul ethanolic extract.

TABLE 3: Marker contents and anti-inflammatory activity of BJK extract after the stability test.

\begin{tabular}{|c|c|c|c|c|c|c|c|}
\hline \multirow{3}{*}{ Testing } & \multicolumn{6}{|c|}{ Marker content mean $(\mathrm{mg} / \mathrm{g}) \pm \mathrm{SD}$} & \multirow{3}{*}{$\begin{array}{l}\mathrm{IC}_{50} \text { on PGE2 inhibition } \\
\\
(\text { mean } \mu \mathrm{g} / \mathrm{mL} \pm \mathrm{SEM})\end{array}$} \\
\hline & \multicolumn{2}{|c|}{ Plumbagin } & \multicolumn{2}{|c|}{ Piperine $\mathrm{b}^{\mathrm{b}}$} & \multicolumn{2}{|c|}{ Myristicin $^{c}$} & \\
\hline & $\begin{array}{l}\text { Content }^{\mathrm{a}} \\
(\mathrm{mg} / \mathrm{g})\end{array}$ & $\%$ remaining & $\begin{array}{l}\text { Content }^{\mathrm{b}} \\
(\mathrm{mg} / \mathrm{g})\end{array}$ & $\%$ remaining & $\begin{array}{l}\text { Content }^{\mathrm{c}} \\
(\mathrm{mg} / \mathrm{g})\end{array}$ & $\%$ remaining & \\
\hline BJK day 0 & $0.86 \pm 0.03$ & 100 & $104.83 \pm 10.11$ & 100 & $4.03 \pm 0.09$ & 100 & $4.42 \pm 0.34$ \\
\hline BJK day 15 & $0.83 \pm 0.01^{*}$ & 97.35 & $94.20 \pm 2.48$ & 89.86 & $2.99 \pm 0.05^{*}$ & 74.25 & $5.24 \pm 0.23$ \\
\hline BJK day 30 & $0.81 \pm 0.01^{*}$ & 94.81 & $105.88 \pm 0.40$ & 101.00 & $3.54 \pm 0.11^{*}$ & 87.92 & $4.64 \pm 0.18$ \\
\hline BJK day 60 & ND & ND & $84.52 \pm 1.36^{*}$ & 80.62 & $3.10 \pm 0.04^{*}$ & 76.85 & $4.23 \pm 1.10$ \\
\hline BJK day 90 & ND & ND & $93.12 \pm 0.76^{*}$ & 88.83 & $3.02 \pm 0.02^{*}$ & 74.91 & $4.18 \pm 0.19$ \\
\hline BJK day 120 & ND & ND & $95.18 \pm 0.65$ & 90.79 & $3.28 \pm 0.06^{*}$ & 81.33 & $4.47 \pm 0.72$ \\
\hline BJK day 180 & ND & ND & $88.98 \pm 1.65^{*}$ & 84.88 & $3.69 \pm 0.03^{*}$ & 91.53 & $1.76 \pm 0.15^{*}$ \\
\hline
\end{tabular}

${ }^{*} P<0.05$; each sample was compared with BJK day 0 using One-way ANOVA statistical analysis. ${ }^{\text {a } D a t a ~ w e r e ~ c a l c u l a t e d ~ f o l l o w i n g ~ t h e ~ s t a n d a r d ~ l i n e a r ~}$ equation: $y=52.702 \mathrm{x}-333.81, R^{2}=0.9982 .{ }^{\mathrm{b}} \mathrm{Data}$ were calculated following the standard linear equation: $y=22.452 \mathrm{x}-1500.8, R^{2}=0.9997$. ${ }^{\mathrm{c}} \mathrm{Data}$ were calculated following the standard linear equation: $y=7.0348 \mathrm{x}-117.11, R^{2}=0.9991$.

of BJK extract, the biological activity should be performed instead of the chemical analysis. Our study has demonstrated that BJK extract was stable at accelerated conditions and could have 24-month shelf-life at room temperature.

\section{Conclusion}

Our findings strongly confirmed the anti-inflammatory activity of BJK and its plant components especially ZOR and
$\mathrm{PCH}$. Increasing the composition of these two plants may increase the anti-inflammatory activity of BJK. Plumbagin and myristicin were the active compounds found in BJK and exerted stronger activity than standard drugs. The results supported its traditional use as an anti-inflammatory drug. BJK showed potent activity in both in vitro and in vivo studies, which persisted through six-month accelerated conditions. Our results also suggested that biological activity, rather than chemical analysis, should be performed in 
BJK stability testing. It can also be concluded that BJK extract could have a 24-month shelf-life under normal room condition. These results supported not only the use of BJK in Thai traditional medicine but also the possibility of further development of phytopharmaceutical products from BJK. This is the first report on in vivo anti-inflammatory activity of $\mathrm{BJK}[\mathrm{E}]$ by topical administration.

\section{Data Availability}

The data used to support the findings of this study are included within the article.

\section{Conflicts of Interest}

The authors declare that they have no conflicts of interest.

\section{Acknowledgments}

This work was supported by Thailand Research Fund through the Royal Jubilee Ph.D. Program (Grant no. PHD/ 0071/2557), the National Research University Project of Thailand, Office of Higher Education Commission, Thammasat University, Centre of Excellence in Applied Thai Traditional Medicine Research, Bualuang ASEAN Chair Professorship, and Faculty of Medicine, Thammasat University, Thailand.

\section{References}

[1] A. Itharat, P. Singchangchai, and P. Ratanasuwan, Wisdom of Southern Thai traditional doctors, Prince of Songkla University, Songkla, Thailand, 1998.

[2] S. Makchuchit, R. Rattarom, and A. Itharat, "The anti-allergic and anti-inflammatory effects of Benjakul extract (a Thai traditional medicine), its constituent plants and its some pure constituents using in vitro experiments," Biomedicine \& Pharmacotherapy, vol. 89, pp. 1018-1026, 2017.

[3] A. Burodom and A. Itharat, "Inflammatory suppressive effect of Benjakul, a Thai traditional medicine on intestinal epithelial cell line," Journal of Medicinal Plants Research, vol. 7, no. 44, pp. 3286-3291, 2013.

[4] F. Begum, Z. Begum, M. Uddin, A. Haider, and R. Barman, "Effects of methanol extract of Piper chaba Stem bark on acute inflammation in rats," Faridpur Medical College Journal, vol. 7, no. 1, pp. 26-28, 2012.

[5] S. Sireeratawong, A. Itharat, N. Lerdvuthisopon et al., "Antiinflammatory, analgesic, and antipyretic activities of the ethanol extract of Piper interruptum Opiz. and Piper chaba Linn," ISRN Pharmacology, vol. 2012, pp. 1-6, 2012.

[6] Z. A. Zakaria, H. Patahuddin, A. S. Mohamad, D. A. Israf, and M. R. Sulaiman, "In vivo anti-nociceptive and anti-inflammatory activities of the aqueous extract of the leaves of Piper sarmentosum," Journal of Ethnopharmacology, vol. 128, no. 1, pp. 42-48, 2010.

[7] R. Maged, N. Nordin, and M. Abdulla, "Anti-inflammatory effects of Zingiber officinale Roscoe roscoe involve suppression of nitric oxide and prostaglandin E2 production," Zanco Journal of Medical Sciences, vol. 17, no. 1, pp. 349-356, 2013.

[8] M. Thomson, K. K. Al-Qattan, S. M. Al-Sawan, M. A. Alnaqeeb, I. Khan, and M. Ali, "The use of ginger (Zingiber officinale
Rosc.) as a potential anti-inflammatory and antithrombotic agent," Prostaglandins, Leukotrienes and Essential Fatty Acids, vol. 67, no. 6, pp. 475-478, 2002.

[9] J.-N. Chen, E. G. De Mejia, and J. S.-B. Wu, "Inhibitory effect of a glycoprotein isolated from golden oyster mushroom (Pleurotus citrinopileatus) on the lipopolysaccharide-induced inflammatory reaction in RAW 264.7 macrophage," Journal of Agricultural and Food Chemistry, vol. 59, no. 13, pp. 70927097, 2011.

[10] R. Brattsand, A. Thalén, K. Roempke, L. Källström, and E. Gruvstad, "Influence of $16 \alpha, 17 \alpha$-acetal substitution and steroid nucleus fluorination on the topical to systemic activity ratio of glucocorticoids," Journal of Steroid Biochemistry, vol. 16, no. 6, pp. 779-786, 1982.

[11] C. A. Winter, E. A. Risley, and G. W. Nuss, "Carrageenininduced edema in hind paw of the rat as an assay for antiinflammatory drugs," Experimental Biology and Medicine, vol. 111, no. 3, pp. 544-547, 1962.

[12] I. C.O. Hamonization, "ICH Harmonised TripartiteStability Guideline: Testing of New Drug Substances and Products," https://www.ich.org/products/guidelines/quality/quality-single/ article/stability-testing-of-new-drug-substances-and-products. html.

[13] S. K. Sandur, H. Ichikawa, G. Sethi, K. S. Ahn, and B. B. Aggarwal, "Plumbagin (5-hydroxy-2-methyl-1,4-naphthoquinone) Suppresses NF- $\kappa$ B activation and NF- $\kappa$ B-regulated gene products through modulation of p65 and $\mathrm{I} \kappa \mathrm{B} \alpha$ kinase activation, leading to potentiation of apoptosis induced by cytokine and chemotherapeutic agents," Journal of Biological Chemistry, vol. 281, no. 25, pp. 17023-17033, 2006.

[14] B. B. Hafeez, J. W. Fischer, A. Singh et al., "Plumbagin inhibits prostate carcinogenesis in intact and castrated PTEN knockout mice via targeting PKC, Stat3, and epithelial-tomesenchymal transition markers," Cancer Prevention Research, vol. 8, no. 5, pp. 375-386, 2015.

[15] J. Y. Lee and W. Park, "Anti-inflammatory effect of myristicin on RAW 264.7 macrophages stimulated with polyinosinic-polycytidylic acid," Molecules, vol. 16, no. 8, pp. 7132-7142, 2011.

[16] R. P. Carlson, O. N.-D. Lynn, J. Chang, and A. J. Lewis, "Modulation of mouse ear edema by cyclooxygenase and lipoxygenase inhibitors and other pharmacologic agents," Agents and Actions, vol. 17, no. 2, pp. 197-204, 1985.

[17] M. Di Rosa, J. P. Giroud, and D. A. Willoughby, "Studies of the mediators of the acute inflammatory response induced in rats in different sites by carrageenan and turpentine," The Journal of Pathology, vol. 104, no. 1, pp. 15-29, 1971.

[18] R. Hirschelmann and H. Bekemeier, "Effects of catalase, peroxidase, superoxide dismutase and 10 scavengers of oxygen radicals in carrageenin edema and in adjuvant arthritis of rats," Experientia, vol. 37, no. 12, pp. 1313-1314, 1981.

[19] P. Crunkhorn and S. C. R. Meacock, "Mediators of the inflammation induced in the rat paw by carrageenin," British Journal of Pharmacology, vol. 42, no. 3, pp. 392-402, 1971.

[20] M. Di Rosa and L. Sorrentino, "The mechanism of the inflammatory effect of carrageenin," European Journal of Pharmacology, vol. 4, no. 3, pp. 340-342, 1968. 